\title{
Gaussian modelling for operator-independent and threshold-free volumetric segmentation of phase sensitive inversion recovery late gadolinium enhanced images
}

\author{
Stefan K Piechnik*, Erica Dall'Armellina, Vanessa M Ferreira, Matthew D Robson
}

From 2011 SCMR/Euro CMR Joint Scientific Sessions

Nice, France. 3-6 February 2011

\section{Aim}

To objectively determine the volume of damage measured by late Gadolinium enhancement (LGE) using threshold-free statistical fit to the distribution of image intensities to reflect the tissue heterogeneity, presence of noise and partial volume effects.

\section{Background}

Infarct size following STEMI carries prognostic significance. Current CMR methods for measuring abnormal myocardium are based on detecting pixels above a certain intensity threshold. This threshold is often defined from a ROI as the mean plus a number (nSD) of standard deviations. This method assumes that the ROI is "normal" and not affected by disease, and is sensitive both to the choice of the ROI and the nSD multiplier. Objective determination of the volume of damage on LGE images may be desirable.

\section{Material and methods}

17 STEMI patients aged $56 \pm 9$ years underwent 3 T CMR imaging within $48 \mathrm{~h}$ post $\mathrm{PCI}$ using a phase-sensitive late-gadolinium enhanced inversion recovery (PSIR) method. Histograms of myocardial signal intensities were calculated in each patient and fitted with a sum of two Gaussians. We calculated the relative volume fraction $\left(\mathrm{Vf}_{\mathrm{Gauss}}\right)$ as the area under the Gaussian distribution with the higher peak divided by the total area under both peaks. For comparison, traditional threshold segmentation was performed based on ROI placed in remote myocardium and varying the threshold nSD

\footnotetext{
University of Oxford, Oxford, UK
}

C 2011 Piechnik et al; licensee BioMed Central Ltd. This is an open access article distributed under the terms of the Creative Commons Attribution License (http://creativecommons.org/licenses/by/2.0), which permits unrestricted use, distribution, and reproduction in any medium, provided the original work is properly cited. from 0 to 6 , to determine the traditional volume fraction $\left(\mathrm{Vf}_{\mathrm{nSD}}\right)$.

\section{Results}

All LGE histograms were accurately described by just two Gaussian components with a high coefficient of explained variation $\mathrm{R}^{2}=0.89-0.98$ (Fig. 1). The lower Gaussian curves were consistently centered near zero ( $\mathrm{SI}=-16 \pm 38$ scanner units[su]) and relatively narrow in distribution $(\mathrm{SD}=39 \pm 12[\mathrm{su}])$. The Upper Gaussian had a greater

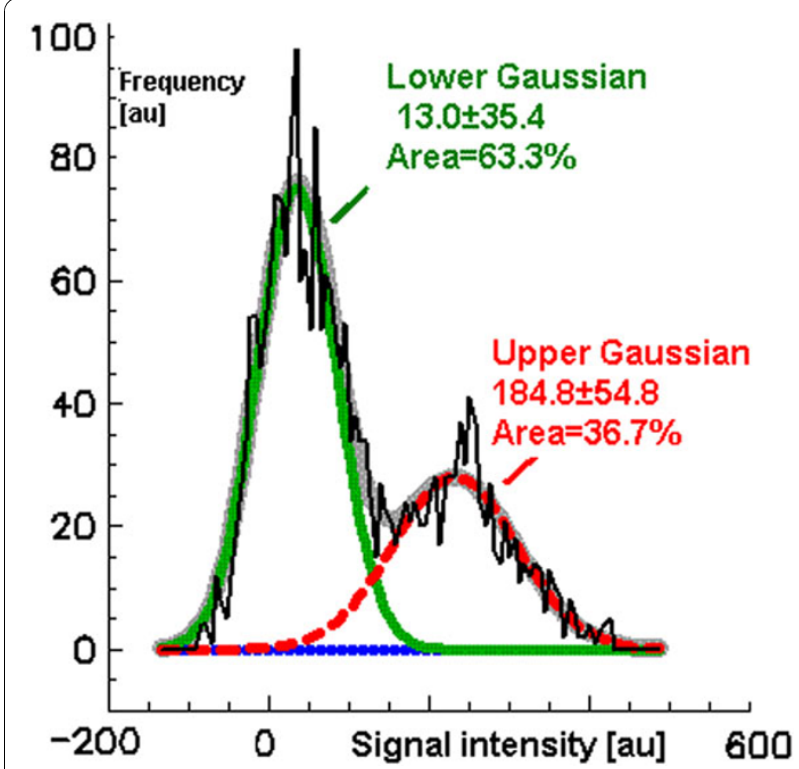

Figure 1 LGE-PSIR pixel intensity histogram fitted with 2 gaussian distributions. 


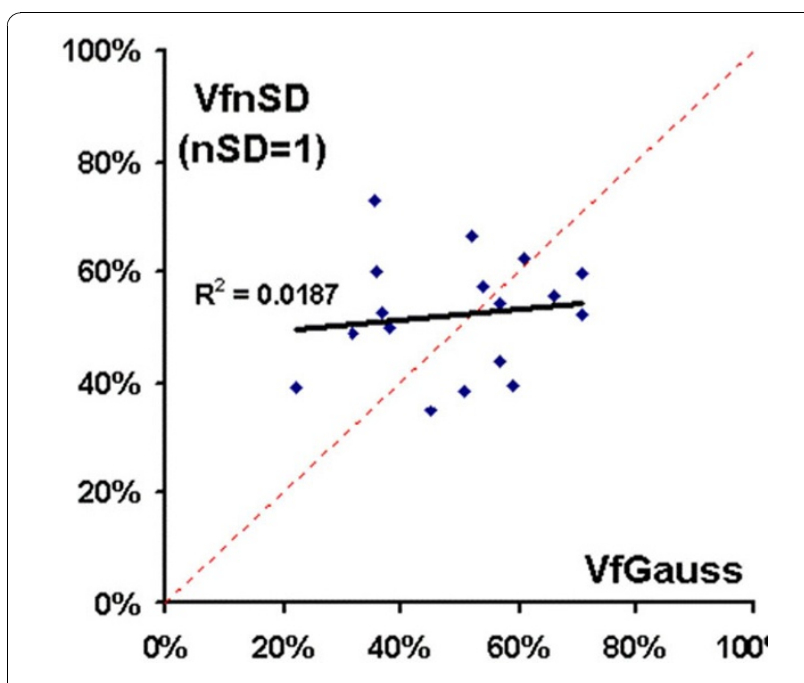

Figure 2 Volume fractions agree for $\mathrm{nSD}=1$, but correlation is weak.

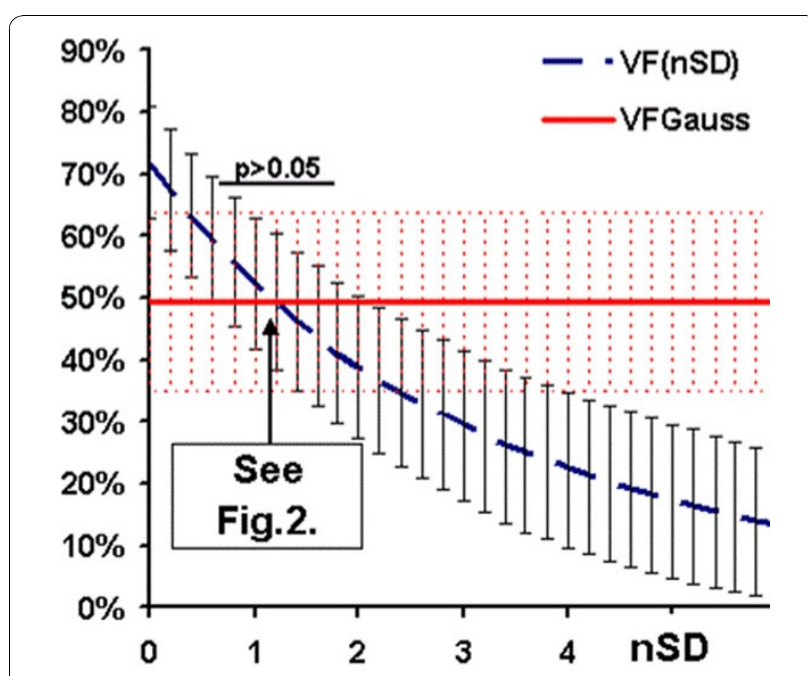

Figure $\mathbf{3}$ Impact of nSD on traditional volume fraction. VfGauss is a constant.

signal intensity $(182 \pm 89$ [su]), and a significantly wider distribution $(\mathrm{SD}=81 \pm 34[\mathrm{su}], \mathrm{p}<0.001)$ than the Lower Gaussian. Average $\mathrm{Vf}_{\mathrm{Gauss}}$ was $49 \pm 14 \%$, which corresponds best to the traditional Vf calculated by using a threshold of about 1.0SD (Fig. 2 Arrow in Fig. 3). Traditional $\mathrm{Vf}_{\mathrm{nSD}}$ strongly depended on $\mathrm{nSD}$ as expected, and there was a significant difference between $\mathrm{Vf}_{\mathrm{nSD}}$ and $\mathrm{Vf}_{\text {Gauss }}(\mathrm{p}>0.05$ ) except for $\mathrm{nSD}=0.8-1.8$ (Fig. 3).

\section{Conclusions}

Gaussian modelling splits the signal intensity distribution consistently into two distinct components: the narrow "normal" peak centred about the null point and a more heterogenous "abnormal" hyperintense pixel distribution. This directly leads to lesion volume fractions that are free from arbitrary choice of ROI or any thresholds, which may improve the consistency and objectivity of LGE image analysis.

Published: 2 February 2011

doi:10.1186/1532-429X-13-S1-P43

Cite this article as: Piechnik et al:: Gaussian modelling for operatorindependent and threshold-free volumetric segmentation of phase sensitive inversion recovery late gadolinium enhanced images. Journal of Cardiovascular Magnetic Resonance 2011 13(Suppl 1):P43.
Submit your next manuscript to BioMed Central and take full advantage of:

- Convenient online submission

- Thorough peer review

- No space constraints or color figure charges

- Immediate publication on acceptance

- Inclusion in PubMed, CAS, Scopus and Google Scholar

- Research which is freely available for redistribution
C Biomed Central 